\title{
Awareness and Practices of Dental Care Waste Management Among Dental Practitioners In Chennai City
}

\author{
Zohara Kayamali Charania ${ }^{1}$, Navin Anand Ingle ${ }^{2}$
}

\begin{abstract}
Objectives:

1. To assess the dentist's awareness about dental care waste management.

2. To know the various methods of bio-medical waste disposal practiced by private dental practitioners in Chennai City.

3. To assess the awareness of dentists regarding colour coding of biomedical wastes.
\end{abstract}

Materials and Methods: A cross sectional questionnaire study was conducted among 250 private dental practitioners selected by simple random sampling.A pretested questionnaire consisting of 28 close ended questions divided into two sections was used.

Results:Out of 250 participants $167(66.8 \%)$ were males and $83(33.2 \%)$ were females.About $14.8 \%$ of the dentists were not aware of the different categories of bio-medical waste generated in their clinic.About $28 \%$ of the dentists were not aware of the bio-medical waste management law in India and the same number (28\%) were not aware of the colour coding for different types of biomedical wastes.

Conclusion: The present study indicates that the majorities of the dental practitioners were not aware of the different categories of biomedical waste and are not practicing the appropriate method of waste disposal. There is an urgent need for continuing dental education on dental care waste management for the dental practitioners.

Key Words: Awareness, Dental practitioners, Bio-medical waste, Management

\section{Introduction}

Bio medical wastes have become a very important source of spreading infections in the society. Hospitals are supposed to be seat of healing, but have become a seat of infection. This is true when it comes to hospital acquired infections which are a frequent picture in those hospitals where health care waste is not managed appropriately.1 Hospital waste is not only infectious but also hazardous and contributes significantly to environmental pollution ${ }^{2}$. It is ironical that we as dental professionals, providing dental care

1 Senior Lecturer, Department of Public Health Dentistry, MGM Dental College and Hospital, Navi Mumbai

2 Professor and Head, Department of Public Health Dentistry, Meenakshi Ammal Dental College, AlappakkamMain Road, Maduravoyal, Chennai

Address for Correspondence:

Dr.Zohara K. Charania

Alipur trust building, E/F Block, $5^{\text {th }}$ Floor, S.B Road,

$2^{\text {nd }}$ Pasta Lane, Colaba, Mumbai 400005

Mob: 9167273074

Email: zohara.charania@gmail.com in hospitals and clinics that bring relief to the sick can create health hazards due to improper management of waste generated in those places. ${ }^{3}$

Dental setup is a multidisciplinary system which consumes lot of items for delivery of dental care ${ }^{2}$. With the advances in technology many improved materials have emerged in the recent past. Many chemicals like acrylics, impression materials and mercury used for restorative purposes may have a possible environmental and human health impact if not handled properly. With the increase in demand for dental care, there has been a rapid growth of dental clinics in the recent years and this led to increase in the amount of bio medical waste generated by them. ${ }^{3}$

This has increased the incidence of nosocomial infections and environmental pollution leading to possibility of many diseases. To protect the environment and community from these hazards, the Ministry of Environment and Forest, Government of India issued a notification on Biomedical waste [management and handling] rules 1998 under Environmental [protection] Act.4 So it is the duty of 
every occupier of a hospital or clinic generating biomedical waste to take necessary steps to ensure that such waste is handled without any adverse effect to the human health and environment. Dental health care setups are found to generate both infectious and hazardous waste, so it is the time for us to get oriented, sensitized and trained to manage health care wastes scientifically. ${ }^{3}$

The present study is a humble effort to know the awareness and practices of dental care waste management among dental practitioners in Chennai, so that training modules can be designed for safer and more effective delivery of dental care.

\section{Aim And Objectives}

\section{Aim}

To study the awareness and practices of Dental care waste management among dentists in Chennai city.

\section{Objectives}

1. To assess the dentists awareness about dental care waste management.

2. To know the various methods of bio-medical waste disposal practiced by private dental practitioners in Chennai city.

3. To assess the awareness of dentist regarding color coding of biomedical wastes.

\section{Materials And Methods}

An epidemiologic survey was conducted to assess the awareness and practices of bio-medical waste disposal among dental practitioners in Chennai city.

1. Source of data

The source of data was primary. It was a survey which included a questionnaire among private dental practitioners at various dental clinics in Chennai.

2. Study population

The survey was conducted among private dental practitioners in Chennai.

3. Ethical clearance

Ethical clearance was obtained from the Institutional Review Board of MAHER (Meenakshi Academy of Higher Education and Research).

4. Sample size

A convenience sample of 250 dentists was decided for the study.

5. Sampling methodology

A simple random sampling is carried out to select the dental practitioners for the study.

\section{Inclusion criteria}

1) They should have a private practice.
2) The clinic should be located in Chennai city.

3) They should be registered with IDA Madras branch

Out of 512 dentists registered with IDA Chennai branch, 250 dentists were selected.

\section{Collection of data}

The study was conducted from August 2009 to December 2009. A specially designed questionnaire consisting of 28 close ended questions divided into two sections is used to assess the awareness and practices of dental care waste management among dental practitioners in Chennai.

The first section of the questionnaire consisted of the questions related to respondent's age, sex, qualification and clinic location. Respondents name was not recorded in order to ensure anonymity. The second section consisted of questions related to the awareness and practices of dental care waste management.

The questionnaire was pilot tested on a small group of dentists who were requested to complete it and to indicate any questions that they found unclear. The qualification of post graduate students who are practicing was considered as BDS.

The dentists were approached personally, the purpose of the study was explained to them and informed consent was obtained. The questionnaire was distributed to them by the investigator and all the questions were explained to avoid any ambiguity. They were assured of the confidentiality of their responses and were requested to give appropriate answers. The filled Questionnaire was collected on the same day or the next day.

\section{Statistical analysis}

The resulting data was coded and statistical analysis was done using SPSS (Statistical Package for Social Sciences) software version 17.0. Mean is calculated for demographic variables and percentages were calculated for the responses gave by the dentists.

\section{Results}

\section{Demographic details}

The age of the participants ranged from 23 years to 64 years with the mean age of 33.7 and other demographic details are given in Table 1. Out of 250 participants $167(66.8 \%)$ were males and $83(33.2 \%)$ were females. $138(55.2 \%)$ participants completed post-graduation and $112(44.8 \%)$ were undergraduates. Of the participants, $121(48.4 \%)$ had been practicing for less than 5 years, 75 (30\%) from 6-10 years and $54(21.6 \%)$ for more than 10 years. 
Table I Demographic details of the participants

\begin{tabular}{lr} 
Variables & No (\%) \\
Gender & \\
Male & $167(66.8 \%)$ \\
Female & $83(33.2 \%)$ \\
\hline Qualification & \\
B.D.S & $112(44.8 \%)$ \\
M.D.S & $138(55.2 \%)$ \\
\hline No. of years in clinical practice & \\
$1-5$ years & $121(48.4 \%)$ \\
6 - 10 years & $75(30 \%)$ \\
$>10$ years & $54(21.6 \%)$ \\
\hline
\end{tabular}

\section{Dentist's responses regarding awareness of dental care wastes}

Table 2 describes the awareness of dental practitioners regarding dental care waste.

About $14.8 \%$ of the dentists were not aware of the different categories of bio-medical waste generated in their clinic.

When asked about the category of an extracted tooth $64.8 \%$ correctly said that it comes under the category of infected waste.

About $39.6 \%$ said they don't know the category of used needles and syringes and only $27.2 \%$ correctly said that it comes under category 4(waste sharps).

Only one third (30\%) of the dentist correctly said that outdated and contaminated drugs come under cytotoxic waste.

With regard to the question about the category of used cotton and impression materials, $39.2 \%$ rightly said that it falls under soiled waste.

About 28\% of the dentists were not aware of the biomedical waste management law in India and the same number $(28 \%)$ were not aware of the color coding for different types of biomedical wastes.

Only $31.6 \%$ correctly said that human anatomical waste should be disposed in yellow color container and $30.4 \%$ said they don't know.

When asked about the color coding for disposing sharp wastes, about $28.4 \%$ said they don't know and only $26.4 \%$ correctly said it should be disposed in blue/ white translucent container.

Figure 1 describes the responses of the dentists regarding the category of developer and fixer solution. Only one third (32\%) of the dental practitioners know that it comes under liquid waste.
Table 2 Awareness of dentists regarding dental care waste Questions

Dentist response (\%)

1. Awareness of different categories of bio medical waste generated in the clinic
a) Yes
$213(85.2 \%)$
b) No
$37(14.8 \%)$

2. Category of an extracted tooth
a) Infected
$162(64.8 \%)$
b) Cytotoxic
c) Infected/cytotoxic
$22(8.8 \%)$
$38(15.2 \%)$
d) Don't know
$28(11.2 \%)$

3. Category of used needles and syringes
a) Category 1
$40(16 \%)$
b) Category 2
c) Category 4
d) Don't know
$43(17.2 \%)$
$68(27.2 \%)$
$99(39.6 \%)$

4. Category of outdated and contaminated medicines
a) Chemical waste
$97(38.8 \%)$
b) Cytotoxic waste
$75(30 \%)$
c) Biotechnological waste
d) Don't know
$33(13.2 \%)$
$45(18 \%)$

5. Category of used impression materials and cotton
a) Solid waste
b) Soiled waste
c) Infected waste
d) Don't know

$65(26 \%)$

$98(39.2 \%)$

$58(23.2 \%)$

$29(11.6 \%)$

6. Awareness of bio medical waste management law in India
a) Yes
$180(72 \%)$
b) No
$70(28 \%)$

7. Awareness of colour coding for different types of biomedical waste
a) Yes
$180(72 \%)$
b) No
$70(28 \%)$

8. Human anatomical waste should be disposed in
a) Yellow container
$79(31.6 \%)$
b) Red container
$73(29.2 \%)$
c) Blue/white translucent container
$22(8.8 \%)$
d) Don't know
$76(30.4 \%)$

9. Sharp wastes should be disposed in
a) Yellow container
$42(16.8 \%)$
b) Red container
$71(28.4 \%)$
c) Blue/white translucent container
$66(26.4 \%)$
d) Don't know
$71(28.4 \%)$

The responses of dentists regarding the question about color coding for outdated and contaminated medicines is given in figure 2 . About $36 \%$ said they don't know and only $34.8 \%$ correctly said that it should be disposed in a black container. 
Figure 1

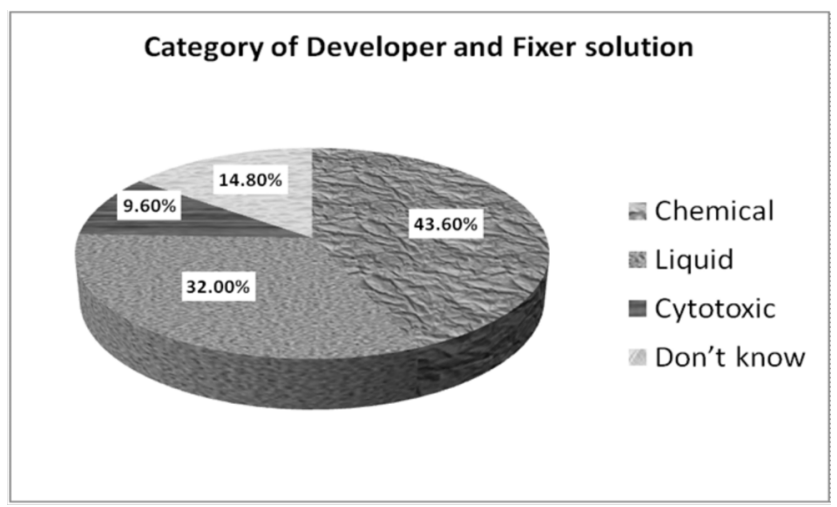

Figure 2

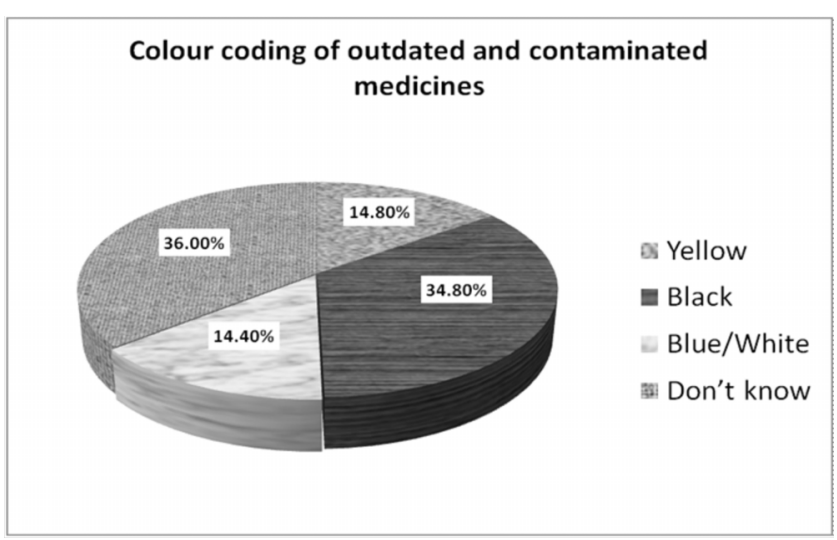

\section{Dentist's responses regarding practices of dental care waste management}

Table 3 describes the practices of the dental practitioners regarding dental care waste management. Only $17.6 \%$ of the dentists segregated the waste.

About $35.2 \%$ of the dentists dispose excess silver amalgam into common bin and $32.8 \%$ of them store it in air tight container with water. Surprisingly $17.6 \%$ of the dentists' don't use amalgam in their clinical practice and only $2 \%$ of them store it in a fixer solution.

To the question regarding the disposal of sharp wastes like needle, $40 \%$ said they will break the needle and dispose and only $24.4 \%$ use needle burner to destroy it which is the ideal method.

Three fourth $(86.4 \%)$ of the dentists dispose the developer and fixer solution by letting into sewer, $50.8 \%$ of them dilute and led into sewer and only $7.6 \%$ return it to the supplier.

Nearly two thirds (69.2\%) of the dental practitioners dispose the lead foil in the common bin and only $3.6 \%$ sell it to certified buyers.

Exposed x-ray films which can be considered as general wastes are disposed in common bin by $75.6 \%$ of the dentists.
Table $3:$ Practices of dental care waste management by dentists

Questions

Dentist response (\%)

1. Segregation of different types of wastes
a) Yes
$44(17.6 \%)$
b) No
$206(82.4 \%)$

2. Storage of excess silver amalgam
a) Dispose to common bin
$88(35.2 \%)$
b) Store in a air tight container with water
$82(32.8 \%)$
c) Store in an air tight container
$31(12.4 \%)$
d) Others (not using/store in fixer)
$49(19.6 \%)$

3. Disposal of infected sharp wastes like needle
a) Dispose to common bin
$83(33.2 \%)$
b) Break the needle and then dispose
$100(40 \%)$
c) Destroy the needle with needle burner
$61(24.4 \%)$
d) Dispose in a puncture proof plastic bag
$6(2.4 \%)$

4. Disposal of developer and fixer solution
a) Led into sewer
$89(35.6 \%)$
b) Diluted and led into sewer
c) Return it to the supplier
$127(50.8 \%)$
$19(7.6 \%)$
d) Others (RVG/no unit)
$15(6 \%)$

5. Disposal of x־ray film lead foils
a) Common bin
$173(69.2 \%)$
b) Stored and disposed in separate container
$53(21.2 \%)$
$9(3.6 \%)$
c) Sell to certified buyers
d) Others (RVG/no unit)
$15(6 \%)$

6. Disposal of exposed X-ray films
a) Common bin
b) Stored separately and disposed
c) Buried in soil
$189(75.6 \%)$
$42(16.8 \%)$
$9(3.6 \%)$
d) Disposed in secured landfill
$4(1.6 \%)$

7. Disposal of orthodontic wires and brackets
a) Common bin
$180(72 \%)$
b) Deform and disposed
$62(24.8 \%)$
c) Sell to certified buyers
$6(2.4 \%)$
d) Others
$2(0.8 \%)$

8. Disposal of outdated and contaminated medicines
a) Common bin
$170(68 \%)$
b) Deform and disposed
$54(21.6 \%)$
c) Buried in soil
$15(6 \%)$
d) Disposed in secured landfill
$11(4.4 \%)$

9. Use of colour coded bags for waste disposal
a) Yes
b) No
$41(16.4 \%)$ $208(83.2 \%)$

10. Final disposal of dental care waste
a) Corporation bin
$224(89.6 \%)$
b) Certified collectors $26(10.4 \%)$

$72 \%$ of the dentists dispose orthodontic wires and brackets in common bin and $24.8 \%$ deform and dispose it. 
Figure 3

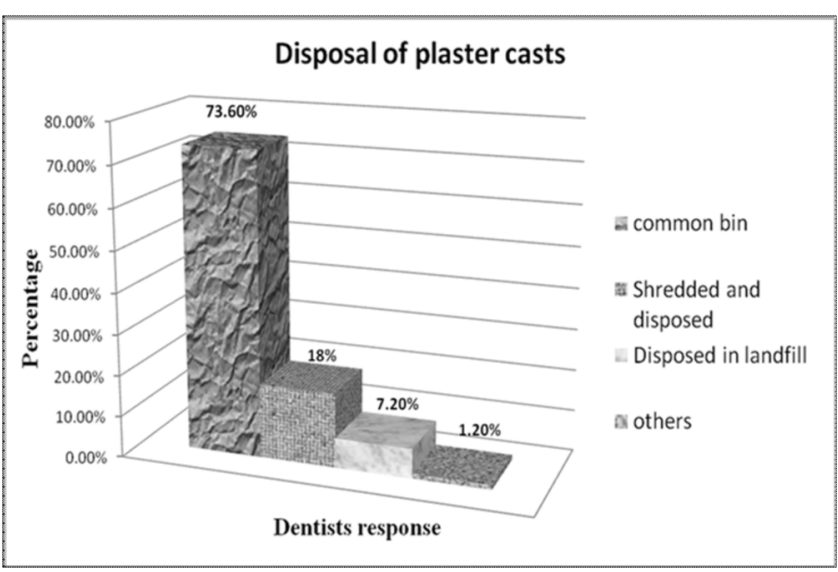

Figure 4

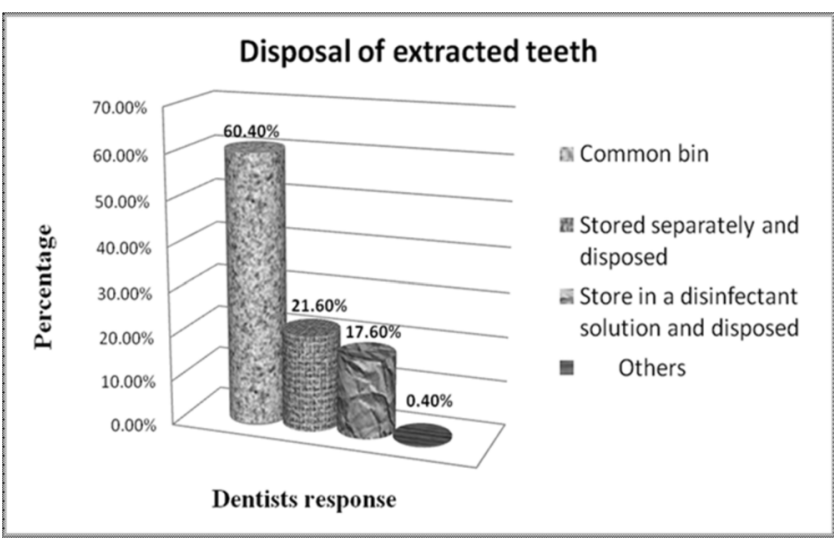

Outdated and contaminated medicines are disposed in common bin by $68 \%$ of the dentists and only $4.4 \%$ dispose it in secured landfill which is the ideal method.

Only $16.4 \%$ of the dentists use color coded bags and about $89.6 \%$ of them dispose the dental care wastes into corporation bin.

Figure 3 gives the responses of dentists regarding disposal of plaster casts. $73.6 \%$ dispose it to common bin and only $18 \%$ shred and dispose.

The response of dentists to the disposal of extracted teeth is given in figure 4 . About $60.4 \%$ dispose it to common bin and only $17.6 \%$ store it in a disinfectant solution and dispose.

\section{Discussion}

This study was an effort to investigate dental practitioners' acquiescence with dental health care waste management procedures in Chennai city. The hazards of waste disposal from dental practices can be divided into two main areas. First, there is a wider environmental burden of a variety of hazardous products and second, the more immediate risks of potentially infectious materials that can be encountered by individuals handling the waste. ${ }^{5}$ The results of this study provide a valuable insight into correct practices in the dental health care waste management and in the corresponding need for improvements to educate the dentists.

In the present study about $14.8 \%$ of the dentists were not aware of the different categories of biomedical waste generated in their clinic which is similar to a study conducted by Sudhir KM et al3 in which $11.1 \%$ were not aware.

$64.8 \%$ said that an extracted tooth comes under the category of infected waste but in the study conducted by Sudhir KM et $\mathrm{al}^{3}$ in Davangere, only $42.1 \%$ said it is an infected waste.

In the present study $72 \%$ of the dentists were aware of the biomedical waste management and handling law in India while in a study conducted by Sudhakar Vet $\mathrm{al}^{6}$ in Bangalore and Kishore et $\mathrm{al}^{7}$ in New Delhi, only $57.6 \%$ and $36 \%$ were aware respectively. This shows awareness of biomedical waste management law varies between cities.

When asked about the color coding for different categories of biomedical waste, $28 \%$ said they are not aware which is similar to the study conducted in Davangere $^{3}(27.2 \%$ not aware).

Majority of the dentists were actually not aware of the different categories of biomedical waste although $85.2 \%$ said they were aware. When subsequent questions were asked about the categories, most of them were not able to answer correctly. The same holds true for the color coding of biomedical waste.

In the present study, about $82.4 \%$ of the dentists do not segregate the wastes generated in their clinic which is similar to the study conducted by Sudhir KMet al3 and Issam Al-Khatib et $\mathrm{al}^{8}$ but in contrast to the study conducted by Sudhakar $\mathrm{V}$ et $\mathrm{al}^{6}$ in which only $35.7 \%$ do not practice segregation.

$35.2 \%$ of the dentists dispose excess silver amalgam into common bin which is similar to the study conducted by Sudhakar V et $\mathrm{al}^{6}$ and Al-Katib et $\mathrm{al}^{9}$, but in the study conducted bySudhir KM et al3only $11.3 \%$ dispose it into common bin. Among 49 (19.6\%) dentists who marked others, 44(17.6\%) were not using amalgam in their clinical practice and only $5(2 \%)$ store it in a fixer solution which is the recommended method by ADA. Management includes disposal if amalgam scrap as hazardous waste or more aptly sent to a recycler. Empty amalgam capsules are to be disposed in the garbage. Since amalgam decomposes on heating, it should not be incinerated. ${ }^{10}$

$33.2 \%$ of the dentists dispose used injection needles into common bin and $40 \%$ break the needle and dispose, but in a Study conducted by Treasure et $\mathrm{al}^{5}$ in New Zealand, only $24.4 \%$ dispose it to common 
bin. In our study the same $24.4 \%$ of the dentists use a needle destroyerto dispose it which is the ideal method. It is of note that in both New Zealand and India there is legislation to ensure the proper disposal of clinical waste.

It was noticed that $50.8 \%$ dispose the developer and fixer solution by letting into sewer which is similar to a study conducted by Darwish et al ${ }^{11}$ in Palestine. Developer solution does not contain silver so it can be diluted and led into sewer, on the other hand fixer solution contains silver, and if led into sewer it will increase the metal load in the sewer which is not allowed as per environmental protection rules. Spent fixer solution contains approximately $4000 \mathrm{mg}$ of silver per litre. ${ }^{10}$ In western countries; they have silver recovery units to reclaim silver. We have to store it separately and hand it over to certified buyers who will extract silver from it.

About $69.2 \%$ dispose the $\mathrm{x}^{-r a y}$ film lead foils into common bin which is not permitted because lead is a heavy metal that affects neurological development and functions. It should not be incinerated nor treated as general waste. It potentially leaches from landfills and can contaminate soil and ground water. Some of the factories may use lead as a raw material for manufacture of batteries but the quantity required is high. ${ }^{10}$

Only $16.8 \%$ stored exposed $\mathrm{x}$-ray films separately which is in contrast to the study conducted by Sudhir $\mathrm{KM}$ et $\mathrm{al}^{3}$ in which half $(52.9 \%)$ of the dentists store it separately. Exposed x-ray films are harmless and can be considered as general wastes.

$72 \%$ dispose orthodontic wires and brackets in to common bin. According to OSHA (Occupational Safety and Health Administration) regulations, orthodontic wires are considered as sharp wastes because the ends of orthodontic wires can penetrate the skin and their contamination with blood can reasonably be anticipated. So they should be disposed as sharp wastes. Orthodontic brackets should be disposed as recyclable wastes. ${ }^{12}$

In the present study $68 \%$ of the dentists dispose outdated and contaminated medicines into common. They are considered as cytotoxic wastes and should be disposed in a secured landfill. ${ }^{4}$

$60.4 \%$ dispose extracted teeth in common bin. OSHA considers extracted teeth to be potentially infectious material that should be disposed in medical waste containers. Extracted teeth sent to a dental laboratory for shade or size comparisons should be cleaned, surface-disinfected with a hospital disinfectant solution. Extracted teeth used for preclinical exercises should be autoclaved before using because liquid chemical germicides do not reliably disinfect both external surface and interior pulp tissue. ${ }^{12}$

$16.4 \%$ of the dentists use colour coded bags for waste disposal in their clinic and only $10.4 \%$ dispose their dental wastes to certified collectors which is similar to a study conducted by Punchanuwat et al1 $1^{3}$ in Bangkok. Whereas in the study conducted by Sudhakar et al ${ }^{6}$ about $33.4 \%$ hand it over to certified agencies.

The validity and reliability of questionnaire based surveys can be influenced by design, question content, analysis and response rates. A significant limitation of this study is that only practitioners who are members of IDA Madras branch were included in this representative sample through simple random sampling. The advantage of using a questionnaire as a data collecting method is the possibility of collecting a lot of data from a large number of respondents relatively quickly and inexpensively. ${ }^{6}$ One disadvantage is 'recall bias', where the respondent's older experiences influence his/her memory.

\section{Conclusion}

The present study indicates that the majorities of the dental practitioners were not aware of the different categories of biomedical waste and are not practicing the appropriate method of waste disposal. Dental health care setups generate number of hazardous wastes that can be detrimental to the environment if not properly managed. We have to address this issue in a practical and meaningful manner. Specialized health care waste management services are available in Chennai but it seems that there is a need for dentists to receive specific information about the availability of these services. Although recommendations can be made to the dental profession to alter their behavior, real improvement is unlikely without changes in legislation and social policy. Safe and effective management of waste is not only a legal necessity but also a social responsibility.

\section{Recommendations}

1. There is an urgent need for continuing dental education on dental care waste management for the dental practitioners.

2. Cooperation between dental associations, governmentrelated ministries and authorities needs to be established, to enhance dental waste management practices.

3. Dentists should try to reduce the biomedical waste generation in their clinic because lesser amount of biomedical waste means a lesser burden on disposal work.

4. In New Zealand, widespread publication of a few cases of inappropriate procedures has helped to raise public and professional awareness of the possible consequences of inadequate procedures. The same can be tried in our country also.

5. A nationwide survey of waste management procedures in dental practices is recommended. 


\section{References}

1. Pushpanjali.K. Dental Health Care Waste and Its Implications. JIAPHD 2004; (4): 8-10.

2. Pushpanjali.K, KH Shaik Hyder Ali, BK Srivatsava. Safe Management of Health Care Waste- A Practical Approach. Journal of Indian Dental Association 2003; 74:29-33.

3. Sudhir KM et al. Awareness and Practices about Dental Health Care Waste Management among Dentists of Davangere City, Karnataka. JIAPHD 2006; (8): 44 to50.

4. Ministry of Forest and Environment. Govt. of India. Biomedical waste [Management \& Handling] rules 1998.India: July 27, 1998 ,

5. Treasure ET, Treasure P. An investigation of the disposal of hazardous wastes from New Zealand dental practices. Community Dent Oral Epidemiol 1997; 25: 328-31.

6. Sudhakar.V, Janakiram Chandrashekar. Dental health care waste disposal among private dental practices in Bangalore City, India. Int Dent J 2008; 58: 51-54

7. Kishore J, Goel P, Sagar B, Joshi TK. Awareness about biomedical waste management and infection control among dentists of a teaching hospital in New Delhi, India. Indian J Dent Res. 2000; 11(4):157-61.

8. Issam Al-Khatib et al. Dental solid and hazardous waste management and safety practices in developing countries: Nablus district, Palestine. Waste Management \& Research 2009; 0: pp. 0734242X09337657v1.

9. Al-Khatib IA, Darwish R. Assessment of waste amalgam management in dental clinics in Ramallah and al-Bireh cities in Palestine. Int J Environ Health Res 2004; 14(3):179-183.

10. Veda Hegde, Kulkarni RD, Ajantha GS. Biomedical waste management. J Oral Maxillofac Path 2007; 11(1): 5-9

11. Darwish RO, Al-Khatib IA. Evaluation of dental waste management in two cities in Palestine. East Mediter Health J 2006;12(2):S217-22

12. United States Department of Labor-Occupational safety and health administration. Dentistry OSHA standards. (Online). Available from: http: //www.osha.gov/SLTC/dentistry/ standards.html. (Accessed 3rd July 2009).

13. Punchanuwat K, Drummond BK, Treasure ET. An investigation of the disposal of dental clinical waste in Bangkok. Int Dent J 1998; 48(4):369-73. 